\title{
NOTA EDITORIAL
}

Por fin nos ha sido posible publicar nuestro tan ansiado monográfico correspondiente al encuentro internacional que la Sociedad Española de Fenomenología organizó en Barcelona, con motivo del I Centenario de la publicación del libro de Husserl Ideas para una fenomenología pura y para una filosofía fenomenológica. Libro primero. Introducción general a la fenomenología pura. La publicación de este libro supuso la puesta de largo del método fenomenológico, que había irrumpido en el campo de la filosofía con la publicación de las Investigaciones lógicas en 1900.

La SEFE no podía dejar pasar este evento, tanto más cuanto fue España el primer país en el que seguramente tal publicación fue comentada. Ortega y Gasset lo anunció en una conferencia del IV Congreso de la Asociación Española para el Progreso de la Ciencia, a mitades de junio de 1913, en la que frente al positivismo que reduce la experiencia a sensación, y al constructivismo que somete la experiencia a regla y compás, la fenomenología da su derecho pleno a la experiencia en la intuición. A continuación inició en El Imparcial una serie de artículos de presentación de la fenomenología partiendo de las tres posibilidades que tenemos para entender el concepto de sensación.

También teníamos que celebrar la presentación de la nueva traducción del texto de Husserl al español, llevada a cabo por el profesor Dr. Antonio Zirión Quijano, en una cuidada edición que incorpora los dos tomos en que Karl Schuhmann reeditó, con significativas ampliaciones y correcciones, la primera edición del recientemente fallecido Walter Biemel. La nueva datación de las correcciones introducidas por Husserl sobre todo con motivo de la traducción de Ideen I al inglés, que ha sido posible por los avances de la crítica en el Archivo de Husserl, convierte en canónica la edición de Schuhmann. Por ello la traducción que tenemos el gusto de presentar en este Encuentro es una insustituible aportación al estudio de la fenomenología en español, evitando con ello, 
además, algunos errores de la traducción anterior que podían distorsionar de manera grave la comprensión de la fenomenología.

El número que presentamos se inicia con la conferencia inaugural a la que fue invitado el Prof. Dermot Moran, por ser uno de los fenomenólogos más estimados en la actualidad, y recoge las ponencias que en el Congreso se referían explícitamente al libro pionero de Husserl. Ha costado mucho esfuerzo sacar adelante este número monográfico, fundamentalmente debido al largo trabajo de las evaluaciones. No nos queda más que agradecer a todos los que han participado con las evaluaciones en la elaboración de este número y, por supuesto, a los autores por su paciencia, trabajo y dedicación. Queremos expresar nuestra gratitud también a todas las instituciones que nos ayudaron a llevar adelante el X Congreso Internacional de la SEFE. "Fenomenología, experiencia y razón. 2013. En el centenario de Ideas I", así como a los organizadores del mismo, al Comité de Apoyo y a los asistentes.

Madrid, primavera de 2015. 